\title{
A Short Note on Climate Change: An Alternative View
}

\section{Peter J. Leggo*}

Department of Earth Sciences, University of Cambridge, UK

${ }^{\star}$ Corresponding author: Dr. Peter Leggo, Department of Earth Sciences, University of Cambridge, UK; Email: peterleggo46@gmail.com

Received: May 19, 2021; Accepted: May 25, 2021; Published: May 30, 2021

It is the general view of the Media that the cause of climate change is directly related to air pollution from coal burning and vehicle exhaust. Undoubtedly this cause of air pollution is a worrying factor but whether it is the cause of climate change can't go unchallenged.

In the geological past evidence of glacial and interglacial periods span a minimum of 400 million year and evidence of glaciation in the Lower Paleozoic, 4-500 million years ago, is seen in the Garevellach Islands and Islay, South West Highlands of Scotland. This event is well documented substantiates the concept of worldwide glaciations throughout the past. This geological evidence appears not to concern the media, apparently due to the lack of understanding of geological science.

In geologically recent times, late $7^{\text {th }}$ to early $19^{\text {th }}$ century, the River Thames periodically froze over to allow the so-called Frost Fairs to take place. No automobiles or electricity generators existed therefore these events could not have been caused by air pollution from these sources.

The controlling factor is more likely to be changes in solar radiation due to alterations in the Earth's orbital around the Sun with time, as this would affect the solar radiation falling on the Earth. In which case there is nothing man can do to alter the situation. 